\title{
AtuaÇÃo de Mulheres Assírias nas Redes de Comércio InTER- Regional do II Milênio AEC: Possibiliddades de Abordagens de GÊNERo nos Estudos da AnTiga MeSOPotâMIA ${ }^{1}$
}

\author{
Anita Fattori ${ }^{2}$
}

\section{RESUMO}

A perspectiva teórica de gênero foi incorporada aos estudos assiriológicos recentemente e os resultados de seu emprego têm mostrado novas possibilidades de abordagem para compreender as sociedades do Antigo Oriente Próximo. No início do segundo milênio $\mathrm{AEC}^{3}$, a cidade de Aššur destaca-se nesse cenário pela sua participação central numa importante rede comercial de longa distância. Os assírios, organizados em empreendimentos familiares, realizavam o comércio de tecido e estanho em troca de ouro e prata. Por meio das cartas intercambiadas entre os mercadores, que tinham como destino principal a Anatólia, e suas famílias que permaneciam em Aššur, podemos constatar a participação ativa das mulheres no empreendimento familiar. Grande parte dessas cartas possui a particularidade de ser enviada ou recebida por mulheres dessas famílias. Assim, essa correspondência constitui uma importante fonte documental para o estudo das mulheres no contexto mesopotâmico. A partir da perspectiva de regimes de gênero, pretendemos apresentar alguns aspectos da atuação das mulheres assírias no contexto do comércio inter-regional do início do segundo milênio AEC para compreender algumas das dimensões de seus papéis sociais.

\section{PALAVRAS-CHAVE}

Mesopotâmia; Período Paleoassírio; Regimes de Gênero.

\footnotetext{
${ }^{1}$ Uma primeira versão deste texto foi apresentada na V Jornada de História Antiga e Arqueologia Clássica da Pontifícia Universidade Católica de Campinas (PUC-Campinas) em 13 de novembro de 2019.

${ }^{2}$ Doutoranda do programa de História Social da Universidade de São Paulo (USP) sob orientação do Prof. Dr. Marcelo Rede. Bolsista FAPESP processo número 2019/12945-6. E-mail: anitafattori@usp.br.

${ }^{3}$ Para as datas da história antiga, a abreviação AEC indica “Antes da Era Comum”.
} 


\section{Introdução}

O imaginário sobre o Antigo Oriente Próximo derivou de diversas percepções sobre o seu passado ${ }^{4}$, por exemplo os relatos de Heródoto ${ }^{5}$ no século V AEC, as descrições medievais das ruínas de Nínive por Benjamin de Tudela ${ }^{6}$ no século XII EC, ou ainda as diversas apropriações dos textos bíblicos, com destaque para as narrativas do Livro dos Gêneses. Apenas no século XIX, em meio ao crescente interesse imperialista pelo Oriente e graças ao desenvolvimento da Arqueologia como disciplina científica, podemos observar o crescimento das pesquisas relacionadas à cultura mesopotâmica. Como nota Zainab Bahrani (2001, pp. 161-179), quando pensamos sobre a Mesopotâmia, especialmente sobre as mulheres mesopotâmicas, muito da produção orientalista do século XIX permeia nosso imaginário, criando contornos disformes sobre essa realidade, como a figura de deusas dotadas de uma sexualidade perigosa, retratadas como femmes fatales, ou a apropriação do harém pelas narrativas orientalistas. Para a autora (pp. 178179), "se as antiguidades recém-descobertas da Mesopotâmia tiveram um forte impacto sobre a imaginação popular e as representações do Oriente na sociedade europeia do século XIX (...)"7, as representações europeias do Oriente também impactaram o imaginário e a produção acadêmica. E impactam até os dias de hoje. Ademais, o reflexo dessas características pode ser percebido quando se trata da história das mulheres nessa sociedade.

No presente artigo, lidamos com o caso específico da atuação de mulheres assírias nas redes de comércio inter-regional do início do segundo milênio AEC. Por meio da análise de cartas enviadas e recebidas por essas mulheres, podemos questionar a visão que reduz a sua experiência social ao ambiente doméstico, rompendo com estereótipos que minimizam suas esferas de atuação.

Em um primeiro momento, apresentaremos algumas características específicas do campo de conhecimento que lida com a documentação escrita do período-a Assiriologia-, e a sua relação com os estudos de gênero, sobretudo a história das

\footnotetext{
${ }^{4}$ Cf. Larsen, 1996.

${ }^{5}$ Heródoto, História, volume 1, $3{ }^{\text {a }}$ Ed., Rio de Janeiro: Editora Nova Fronteira, 2019.

${ }^{6}$ Uma tradução crítica dos relatos de Benjamin de Tudela pode ser encontrada em: Adler, M. N. The Itinerary of Benjamin of Tudela. Critical Text, Translation and Commentary. Londres: Oxford University Press, 1907.

7 "If the newly discovered Mesopotamian antiquities had a strong impact on the popular imagination and the representations of the East in nineteenth-century European society (...)".
} 
mulheres. Consideramos que realizar o escrutínio crítico das bases sobre as quais nossa pesquisa foi e continua a ser produzida pode nos levar a uma aproximação mais consciente de nossos objetos de pesquisa. Esse é um exercício epistemológico direcionado ao estabelecimento de novos olhares sobre essas sociedades. Em seguida, examinaremos o contexto de produção dessas cartas. Para tanto, apresentaremos publicações e análises contemporâneas desses documentos, evidenciando as particularidades do caso paleoassírio. Por fim, apresentaremos uma possibilidade de análise para o caso paleoassírio ao mobilizar a noção de regimes de gênero (SebillotteCuchet, 2012), com o objetivo de compreender como a atuação das mulheres no contexto histórico das redes de comércio inter-regional do início do segundo milênio produziu especificidades em relação ao lugar social ocupado por elas. Ademais, pensar nos diversos regimes de gênero que operam nas sociedades, no gênero como um processo de construção social, nos leva, sobretudo, a uma reflexão contemporânea sobre nossas próprias relações sociais.

\section{Assiriologia e história das mulheres: breves apontamentos}

A Assiriologia é o campo de pesquisa voltado aos estudos relacionados à cultura mesopotâmica, que teve lugar no Antigo Oriente Próximo entre o quarto e o primeiro milênio AEC. No percurso inicial da Assiriologia, em meio à confirmação da decifração do cuneiforme acadiano, na segunda metade do século XIX ${ }^{8}$, alguns traços específicos do seu desenvolvimento vão marcar as condições da consolidação do campo: enraizado em uma tradição filológica que, por muito tempo, esteve atrelado aos estudos bíblicos e aos estudos orientais. Apenas em 1950, quase cem anos após a decifração do cuneiforme acadiano, pode-se considerar o marco emancipatório da Assiriologia. Acontece, pela primeira vez, o Encontro Internacional de Assiriologia, ou $\mathrm{RAI}^{9}$, criando um espaço de discussão das produções acadêmicas de forma totalmente autônoma.

Em relação às especificidades das fontes cuneiformes, algumas características também merecem destaque. São elas que nortearão nosso entendimento de como o campo

\footnotetext{
${ }^{8}$ Sobre a história da decifração do cuneiforme, cf. Lion e Michel, 2007.

${ }^{9}$ RAI, ou Rencontre Assyriologique Internationale, acontece anualmente desde 1950, com exceção dos anos de 1954, 1957, 1968, 1973, 1990, 1999 e 2020. A última edição, a de número 65, aconteceu em Julho de 2019, na cidade de Paris.
} 
lidou com essa documentação. A maior quantidade de fontes cuneiformes é formada por tabletes de argila. Alguns especialistas estimam que, hoje, temos acesso a cerca de um milhão de tabletes que abrangem uma extensão temporal de aproximadamente 3200 AEC a 75 EC. A necessidade incontornável de dedicar-se à edição dos documentos cuneiformes, procedimento que envolve a transliteração/transcrição e tradução desses documentos, fez com que os assiriólogos construíssem seu conhecimento sobre as bases teórico-metodológicas da Filologia. A prevalência de uma base filológica não levou apenas a uma falsa impressão de neutralidade no campo, mas também à demora para incorporar tendências de análise de outros campos de pesquisa e a participar de debates variados das Ciências Humanas. Como resultado, percebe-se um certo isolamento e ausência de uma consciência teórica mais apurada (Veldhuis, 2018, pp. 448-449). Podemos citar, como exemplo, a demora do campo em incorporar as discussões do movimento chamado material turn, presente nas Ciências Humanas desde os anos de 1980, mas que, apenas nessa década, entraram efetivamente em pauta nos estudos de Assiriologia, a exemplo do livro Texts and Contexts. The circulation and the Transmission of the Cuneiform texts in Social Space, editado por P. Delnero e J. Lauinger $(2015)^{10}$.

Aliada à abundância de fontes, temos a proximidade entre o contexto de exumação e o seu contexto de uso e produção, ou seja, como explica Eva Von Dassow (2018, p. 821), muitas das fontes cuneiformes “(...) são contemporâneas aos eventos que ocasionaram sua escrita, e todas têm uma relação direta com o momento a que se referem (...)"11. A título de exemplo, podemos citar as cartas enviadas pelas mulheres assírias no contexto do comércio inter-regional do início do segundo milênio. Algumas delas tratam do envio de tecidos para os maridos que estão na Anatólia e documentam efetivamente transações comerciais realizadas naquele momento, como no trecho: "O tecido espesso que te enviei pela caravana de Aššuriš-tikal, filho de Sukkallīya, ele chegou para ti." 12 (CCT 4, 21B, linhas 4-8) ${ }^{13}$. Essa particularidade trouxe consigo uma falsa ilusão de objetividade em relação ao estudo das fontes, ou, nas palavras da autora (p. 819), levou a

\footnotetext{
${ }^{10}$ Sobre o material turn cf. Hicks, 2010, pp. 25-98.

11 “(...) are contemporaneous with the events that occasioned their writing, and every one bears a direct relationship to the moment that refers to (...)"

${ }^{12}$ As normalizações e traduções do acadiano apresentadas nesse artigo são de minha autoria.

${ }^{13}$ Smith, S. Cuneiform Texts from Cappadocian Tablets in the British Museum part. IV, $1927=$ CCT 4 , 21b, linhas 4-8, enviada por Lamassī para seu marido Pūšu-kēn e seu cunhado Aššur-malik. No texto acadiano temos: "1(diš) șubātam kabtam ša ina ellatum Aššuriš-tikal mār Sukkalliya ša ušébiluka illikam”.
} 
um "positivismo ingênuo", como se a realidade estivesse congelada frente aos nossos olhos e pudéssemos reproduzi-la e recuperá-la tal como realmente foi.

A permanência de abordagens tradicionais e a resistência em incorporar novos debates no campo é visível quando tratamos dos estudos das mulheres na documentação cuneiforme. Grande parte dessas pesquisas, até os dias de hoje, está assentada em um "duplo androcentrismo": o estabelecido pelas fontes - sabemos que a grande maioria das fontes era produzida por homens e para homens - e o estabelecido pelo campo de estudo-a maior parte das produções assiriológicas é de autoria masculina e guiada por essa ótica de interpretação (Couto-Ferreira \& Garcia-Ventura, 2014, p. 120; Harris, 2000, p. viii). Também podemos notar que a produção acadêmica se concentrou, sobretudo, em estudos de deusas e mulheres da elite, como rainhas e sacerdotisas, e nas investigações sobre os usos e condições dos corpos femininos, especialmente relativos à maternidade e prostituição (Garcia-Ventura, 2016a; 2016b, pp. 20-24).

A primeira publicação abrangente sobre o papel das mulheres na sociedade mesopotâmica, La femme dans la Mésopotamie ancienne, de Jean Bottéro, data de 1965, mas apenas na década de 1980 temos uma preocupação efetiva em relação à presença das mulheres na documentação cuneiforme com a organização da $33^{\circ}$ RAI (1986), em torno do tema La femme dans le Proche-Orient Antique, em Paris. Como podemos notar, as abordagens preocupadas com a história das mulheres no Antigo Oriente Próximo são recentes e é evidente que o campo da Assiriologia dedicou-se algum tempo a apenas trazer à tona a presença de mulheres na documentação. No que diz respeito às discussões sobre a relação entre gênero e sociedade, presente no âmbito das Ciências Humanas desde a década de 1970, estas são incorporadas no campo assiriológico apenas nos anos 2000, com destaques para: a criação de uma revista com foco em estudos de Egiptologia e Antigo Oriente Próximo, a NIN-Journal of Gender Studies in Antiquity ${ }^{14}$; a realização da $47^{\circ}$ RAI em Helsinque, em 2001, intitulada Sex and Gender in the Ancient Near East; e a organização do primeiro Workshop on Gender, Methodology and the Ancient Near East por Agnès Garcia-Ventura e Saana Svärd, que atualmente encontra-se em sua terceira edição (Helsinque em 2014, Barcelona em 2017 e Gent em 2019) ${ }^{15}$. Vale ressaltar

\footnotetext{
14 A revista tem quatro volumes publicados entre os anos 2000 e 2003. Pode ser acessada em: (https://brill.com/view/journals/nin/nin-overview.xml) (Lion, 2007, p. 53).

15 Para uma visão mais detalhada da discussão, cf.: Asher-Grave, 1997, p. 236; Bahrani, 2001, pp. 7-27; Garcia-Ventura \& Zisa, 2017, pp. 38-39; Garcia-Ventura \& Justel, 2018, p. 28; Lion, 2007, pp. 51-54; Svärd, 2015, pp. 8-12.
} 
que, quando pensamos em estudos de gênero, eles se concentram, em sua maioria, em estudos sobre as realidades contemporâneas, e que muito das discussões que tratam “(...) [d]os períodos da Antiguidade até o século XVII são frequentemente negligenciados ou simplificados" (Lett, 2012b, p. 569) ${ }^{16}$.

Nesse sentido, os estudos das mulheres paleoassírias apresentam “(...) uma rara ocorrência da visibilidade óbvia das mulheres em uma arena-registros escritos sobre comércio público ou privado-em que os homens geralmente são mais visíveis (...)" (Thomason, 2013, p. 108) ${ }^{17}$. Por meio dessas cartas, enviadas ou recebidas por essas mulheres, podemos nos aproximar de uma realidade muito particular do Antigo Oriente Próximo: o cotidiano de mulheres comuns. Contudo, mais do que evidenciar a presença dessas mulheres na documentação, podemos nos questionar sobre as abordagens aplicadas até então para a história das mulheres, refletindo sobre a pluralidade de atuação dessas figuras dentro da sociedade paleoassíria.

\section{Atuação feminina no comércio de longa distância durante o período paleoassírio:} contexto e perspectivas historiográficas

O chamado período paleoassírio não remete apenas ao recorte temporal, que se estende de 2025 a $1809 \mathrm{AEC}^{18}$, mas também à cultura e ao dialeto da língua acadiana ${ }^{19}$ que se desenvolvera na região de Aššur (Michel, 2001, p. 13; Veenhof \& Eidem, 2008, pp. 20-21). Nesse período, Aššur - atual Al-Sharqat, no norte do Iraque - encontrava-se no centro de uma extensa rota comercial inter-regional “(...) que conectava o Sul da Mesopotâmia e o Elam com a Anatólia" (Veenhof, 2017, p. 61) ${ }^{20}$.

Os mercadores assírios partiam de Aššur principalmente para a Anatólia carregando consigo estanho e grandes quantidades de tecido em caravanas de asnos, e recebendo em troca ouro e prata para, por exemplo, reinvestir nos seus negócios (Fig. 1). Uma vez na

\footnotetext{
16 “(...) les périodes de l'Antiquité au XVII e siècle sont donc souvent ignorées ou simplifiées”.

17 “(...) a rare occurrence of the obvious visibility of the women in an arena - written records about public or private commerce - in which males are typically more visible (...)"

18 De acordo com Klass R. Veenhof (2017, p. 57), o chamado período paleoassírio engloba os acontecimentos que ocorreram entre os anos de 2025 AEC, quando a cidade de Aššur torna-se independente do domínio e influência de Ur III, e 1809 AEC, quando o rei amorita Šamiši-Adad I derruba a dinastia local de Puzur-Aššur I.

${ }^{19} \mathrm{O}$ acadiano, em suas diversas variantes, é uma língua semítica, que foi usada entre o terceiro e primeiro milênio AEC na região da antiga Mesopotâmia.

20 “(...) that linked Southern Mesopotamia and Elam with Anatolia”.
} 
Anatólia, os mercadores podiam solicitar mais mercadorias, as quais eram então levadas em comboios e caravanas de parceiros comerciais ou transportadores. O tecido era produzido na casa dos mercadores assírios, em Aššur, “(...) em um ateliê onde trabalhavam todas as mulheres da unidade doméstica, incluindo crianças e servas" (Michel, 2001, p. 421) ${ }^{21}$, alimentando, assim, o negócio familiar.

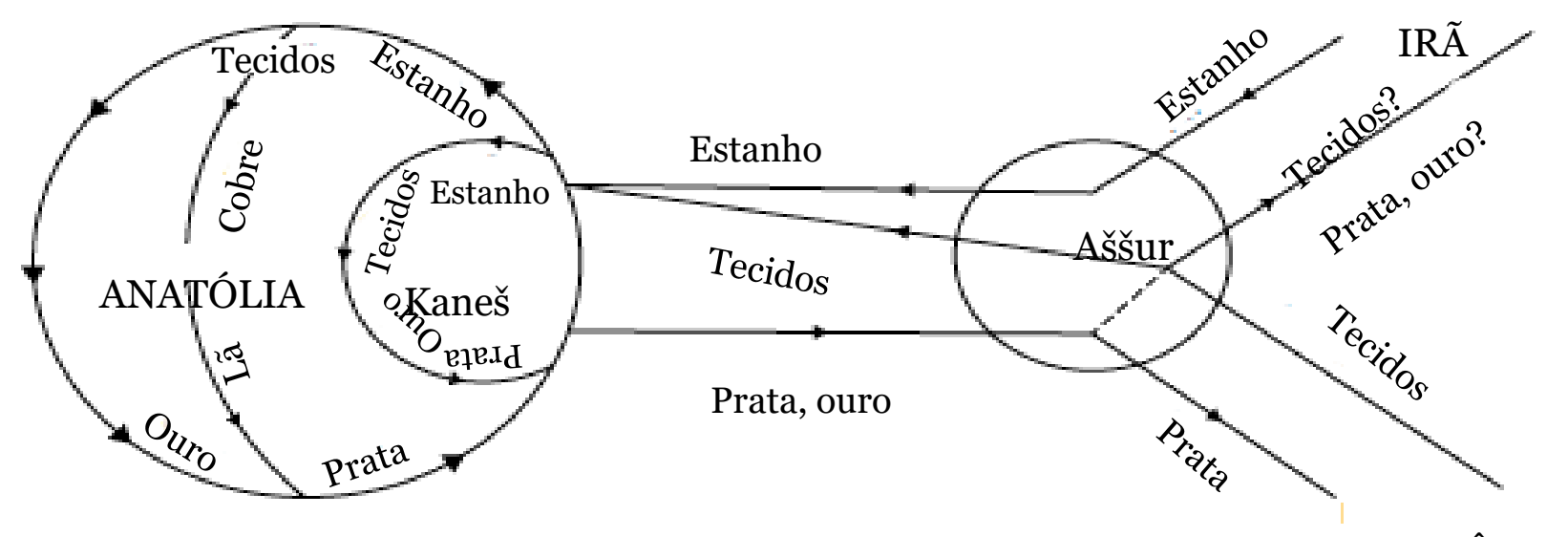

BABILÔNIA

Figura 1: Aššur e o comércio de longa distância do início do segundo milênio Fonte: adaptado de Veenhof, 2017, p. 61.

O comércio, portanto, era controlado essencialmente por essas organizações familiares. Assim, como afirma Michel (2017, p. 91), acreditamos que "os laços familiares formaram a base de muitas relações profissionais" 22 , e que a família, em um sentido amplo, designaria um “(...) grupo de pessoas relacionadas por laços de parentesco, ou seja, pela filiação e pelas alianças de casamento (ou laços de afinidade)" (Rede, 2007, p. 22). Vale ressaltar que o parentesco "é um sistema de categorias e estatutos que muitas vezes contradizem relações propriamente genéticas. Há muitos exemplos nos quais o estatuto de parentesco defendido socialmente prevalece sobre a biologia" (Rubin, 2017, p. 21), como na Mesopotâmia, onde "a filiação legítima pode ser real ou fictícia (por adoção) etc" (Rede, 2007, p. 22).

Os diferentes grupos familiares interagiam entre si, formando uma complexa rede de negócios inserida no contexto do comércio de longa distância. Além disso,

21 “(...) dans un atelier où travaillent toutes les femmes de la maisonnée, enfants et servantes comprises”.

22 "Family ties formed the basis of many professional relationships". 
individualmente os mercadores também participavam de associações comerciais de diversas naturezas, podendo ser, por exemplo, associações de longa data, ou, simplesmente, contratos de uma única viagem. Portanto, para além de pessoas que pertenciam a uma mesma família, as organizações familiares englobavam “(...) um circulo muito mais amplo de indivíduos (...)" (Larsen 2007, p. 103) ${ }^{23}$. Os laços de parentesco e os laços comerciais se sobrepunham, a exemplo do vocabulário empregado nas relações comerciais, o qual, por sua vez, derivava do vocabulário empregado para definir as relações familiares. A expressão bēt abini ${ }^{24}$, literalmente 'a casa de nosso pai', poderia apresentar diversos sentidos na documentação paleoassíria: como "família", "patrimônio", "firma", "lugar da família" (Cad A.1, p. 73); significados estes que emergem das diversas camadas das relações possíveis nesse contexto. Levando em conta essas considerações, as organizações familiares, ou firmas familiares, são tomadas nesse texto com o sentido de um grupo de pessoas alinhadas com propósitos comerciais.

A participação dos mercadores assírios nessa rede comercial era viabilizada, sobretudo, pelo relacionamento entre Aššur e a Anatólia. Para possibilitar as longas viagens esses mercadores contavam com entrepostos comerciais estabelecidos na Anatólia. Os entrepostos menores recebiam o nome de warbatum, e eram subordinados ao kārum, os núcleos principais de estabelecimento dos comerciantes assírios (Veenhof, 2003, p. 84). Dentre eles, destacamos Kaneš, atualmente Kültepe, na Turquia, onde grande parte dos mercadores assírios se estabeleceu por longos períodos.

É também em Kaneš que encontramos a maior parte da documentação sobre o período paleoassírio, já que, até os dias atuais, poucas informações sobre esse momento da história de Aššur foram recuperadas durante as escavações em seu território (Barjamovic, Hertel \& Larsen, 2012, p. 57). Cerca de 23 mil tabletes, que datam de aproximadamente 1945 a 1835 AEC, foram escavados dos arquivos privados das casas dos mercadores, as quais ficavam localizadas na parte baixa da cidade (Michel, 2018, p. 48; Veenhof, 2003, p. 78; p. 83). Esses arquivos de documentos dizem respeito à vida de três ou quatro gerações da família desses mercadores. Dentro desses arquivos encontramos uma vasta quantidade de documentos legais, como contratos de transportes

\footnotetext{
23 “(...) a much wider circle of individuals (...)".

${ }^{24}$ Para uma discussão mais aprofundada do termo bèt abini, cf. Larsen, 2007; Veenhof, 2014.
} 
e notas promissórias; listas de diversas naturezas e memorandos, como detalhamento de pacotes de prata; e cartas (Veenhof, 2013, pp. 37-38).

As cartas, em acadiano referidas pelas palavras țppum, "tablete", ou našpertum, “mensagem", representam cerca de 30 a 50\% desses arquivos (Veenhof, 2013, p. 37) A eficácia da comunicação à longa distância era primordial para o funcionamento do comércio, sendo a forma mais eficiente de conectar comerciantes-em deslocamento constante ou estabelecidos em Kaneš-, com suas famílias e parceiros que permaneciam em Aššur (Michel, 2018, p. 52). Apesar da grande maioria dos documentos epistolares não ser datada, a quantidade de cartas encontradas e o uso frequente de algumas expressões de temporalidade, como "assim que você ler meu tablete, envie sua resposta", ou "se eu não te escrever em 10 dias, não conte com isso" (Stratford, 2017, p. 167), evidenciam que a comunicação era frequente e rotineira, amparada numa temporalidade conhecida e mobilizada por aqueles agentes.

De acordo com Stratford (pp. 162-179), em comparação à duração de percurso das caravanas dos mercadores - uma viagem de aproximadamente 30 dias $^{26}$-, as cartas demoravam metade do tempo para chegar ao seu destino, o que fez o autor considerar que o sistema de comunicação era extremamente eficiente ${ }^{27}$. Essa relativa facilidade na comunicação não impactava apenas na concepção de tempo para os assírios, como também na otimização do tempo do comércio, estendendo o campo de possibilidade de ação desses mercadores. Por isso, consideramos as cartas como parte do fenômeno comercial, e não apenas um mecanismo intermediário ou complementar do processo mercantil.

Uma particularidade dos documentos epistolares desses arquivos é a presença de mulheres - mães, esposas, filhas dos mercadores_em 20\% dos cabeçalhos dessas cartas. O dado mais recente é o de que temos acesso a cerca de 400 cartas exumadas desses

\footnotetext{
${ }^{25}$ Dentre as publicações, destacamos a obra "Correspondance des marchands de Kanish au début du IIe millénaire avant J.-C.”, de Cécile Michel (2001), a maior obra sobre essa documentação, que apresenta a tradução de 400 dessas cartas.

${ }^{26} \mathrm{O}$ trajeto percorrido pelos mercadores assírios e a sua duração é alvo de debate entre diversos autores. C.f. Barjamovic (2011, p. 15); Larsen (2015, pp. 175-176); Altawell \& Squitieri (2018, p. 174).

${ }^{27}$ As fontes evidenciam a ocorrência de diversos tipos de termos conectados à figura dos mensageiros, pessoas designadas à entrega de documentos, como é o caso do termo bätiqum (CAD, v. 7, p. 82; v.2, p. 106; Veenhof, 2008). Essas pessoas faziam uso de meios de transporte mais eficientes para percorrer o trajeto entre a Mesopotâmia e a Anatólia, como cavalos e mulas. Outra observação importante é a relação entre o comércio e o envio de cartas. Notamos que o envio desses documentos não estava condicionado à parceria entre os mercadores e podia ser feito através de uma caravana (ellutum) qualquer (Stratford, 2017, p. 175).
} 
arquivos que apresentam mulheres como remetentes ou destinatárias (Michel, 2009, p. 254). As cartas mesopotâmicas escritas durante o $2^{\circ}$ milênio, em sua maioria, apresentam uma estrutura e um estilo retórico próprio em sua composição. No cabeçalho dessas cartas encontramos a seguinte fórmula: "para [remetente] diz, assim [destinatário] [diz]"28, e é por meio do estudo onomástico dos nomes dos remetentes e destinatários que conseguimos detectar a presença de mulheres na comunicação epistolar ${ }^{29}$. Para além de um panorama sobre o comércio de longa distância, essas cartas nos fornecem informações importantes sobre o dia a dia dessas pessoas-como requisições, reclamações, confirmações - uma vez que, mais do que parte do arquivo de mercadores, esses documentos foram parte dos arquivos privados das famílias assírias. Logo, eles são uma importante fonte para a história de mulheres dessa sociedade.

Por muito tempo, o estudo dos documentos sobre mulheres nos arquivos dos mercadores de Kaneš evidenciou a presença de figuras femininas na documentação sem problematizar o lugar que ocupavam nessa sociedade, retratando-as através da ótica dicotômica da divisão artificial das esferas sociais do público e do privado. Se, por um lado, as ações das mulheres estavam restritas à unidade doméstica (privado), por outro, os homens participavam ativamente do comércio e da política (público).

As noções de público e privado, que surgem em um contexto ocidental pósRevolução Industrial, são categorias de análise anacrônicas para interpretar a realidade das mulheres assírias. Nesse sentido, é necessária atenção à forma como o próprio domínio doméstico foi pensado. Como discutido por Marilyn Strathern (2016, p. 65), a naturalização do modelo inglês/estadunidense da housewife levou à criação de estereótipos do lugar social de mulheres ao longo da história. O ambiente doméstico foi, assim, concebido e reduzido a uma unidade feminina isolada e desarticulada de contextos sociais mais amplos (Rocha, 2018, p. 300). Essa visão do espaço doméstico como feminino por excelência contamina nosso olhar para o passado, tendo, como consequência, a redução não apenas da experiência feminina ao domínio doméstico, mas também a redução desse espaço como sendo exclusivamente feminino.

\footnotetext{
${ }^{28}$ Em acadiano: "ana [remetente] qib̄i-ma umma [destinatário]-ma".

${ }^{29}$ Vale ressaltar que a fórmula do cabeçalho das cartas paleoassírias não aparece necessariamente nessa ordem, já que o primeiro componente era, em geral, o sujeito de maior prestígio social (Michel, 2001, p. 421).
} 
Além disso, essa visão reforça a ideia da ausência de uma agência feminina, na qual os homens assumem o papel de atores centrais, enquanto as mulheres figurariam como coadjuvantes sociais. Como nota Alison Thomason (2013, p. 105), “(...) os estudiosos modernos usualmente concluíam que as mulheres eram os suportes das firmas familiares, e não conduziam as decisões dos negócios, muito menos independentes ou empreendedoras por direito próprio" ${ }^{30}$. Nesse artigo, a autora busca entender a construção da agência feminina através da produção e comercialização dos tecidos ${ }^{31}$ e ilustra os apontamentos destacados acima com exemplos de publicações de Veenhoff e Günbatti, que apresentaremos a seguir (Thomason, 2013, pp. 105-106).

Em um artigo de 1977, Klass R. Veenhof (p. 113) afirma que “(...) as esposas de vários mercadores, na ausência de seus maridos $^{32}$, passaram a atuar como chefes do

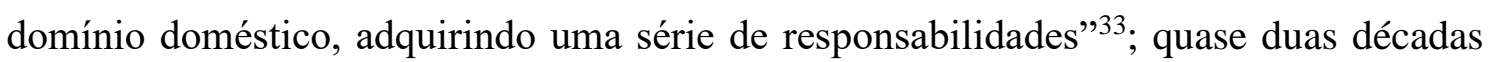
depois, em 1992, Cahit Günbatti (p. 234) conclui que as “(...) mulheres na Assíria no início do $2^{\circ}$ milênio A.C. eram quase tão ativas quanto os homens ${ }^{34}$ em questões da vida social” ${ }^{35}$. Se, de um lado, tais interpretações extrapolaram o binômio público-privado, correlato ao masculino-feminino, e realçaram uma atuação das mulheres, por outro, a perspectiva desses autores ainda minimizava a ação feminina, corroborando a ideia de que a atuação feminina externa à esfera do privado aparecia exclusivamente quando da "ausência de seus maridos". Nos últimos anos, algumas publicações passaram a questionar essas abordagens, ressaltando a agência dessas mulheres nas redes de comércio inter-regional do início do segundo milênio, com destaque para a vasta produção de Cécile Michel $^{36}$, que recentemente publicou um volume dedicado ao estudo das mulheres de Aššur e Kaneš (2020).

\footnotetext{
30 "For until very recently, the modern scholars usually concluded that the women were the supporters of the family firms, and not driving the business decisions, much less independent or entrepreneurial in their own right".

${ }^{31}$ A autora apresenta novos apontamentos sobre essa publicação em um artigo de 2018 (Thomason, 2018).

${ }^{32}$ Grifo nosso.

33 " (...) various merchants' wives, in the absence of their husbands, came to function as heads of the households, acquiring quite a number of responsibilities".

${ }^{34}$ Grifo nosso.

35 “(...) women in Assyria at the beginning of 2nd millennium B.C. were almost as active as men in matters of social life".

${ }^{36}$ Cf. Michel, 2001; 2004; 2006; 2008; 2009; 2015; 2017, 2020.
} 


\section{Possibilidade de abordagem no caso paleoassírio: regimes de gênero}

Nas palavras de Violaine Sebillotte-Cuchet, “(...) não é mais possível concordar com a premissa de que o sexo de um indivíduo, independente do contexto, automaticamente e naturalmente o consigna a uma rede de significados específicos (...)" $\left(2012\right.$, p. 577) ${ }^{37}$. Partindo dessa proposição, organizaremos a pesquisa histórica a partir da análise do contexto discursivo do período paleoassírio, e não de pressupostos apriorísticos do masculino-público e do feminino-privado. Isto posto, mobilizaremos no presente estudo a noção de regimes de gênero para nos aproximar dessa realidade social específica.

Em poucas palavras, um regime de gênero “(...) pode ser definido como um agenciamento particular e único das relações de sexo dentro de um contexto histórico, documental, e relacional específico" (Lett, 2012b, pp. 565-566) ${ }^{38}$. Esses regimes surgem dentro de limites estabelecidos em um espaço comparativo, sendo esse espaço preenchido pelas diferenças de gênero (Sebillotte-Cuchet, 2012, pp. 577-578).

A aplicabilidade da noção de regimes de gênero pode ser exemplificada pelo artigo de Didier Lett sobre o contexto medieval italiano, Genre et paix. Des mariages croisés entre quatre communes de la Marche d'Ancône en 1306 (2012a). Nesse artigo, o autor explora um tratado de paz, assinado em 1306 E.C., que se referia ao casamento cruzado de 140 homens e 140 mulheres “(...) socialmente muito diferenciados, inseridos em uma complexa rede de relações, habitando quatro comunas (...)" (p. 632) ${ }^{39}$ em situação de conflito que integravam a província de Marca de Ancona, parte dos Estados Pontifícios. Nessa investigação, Lett parte do instigante questionamento sobre o “(...) significado simbólico e social desses casamentos cruzados, metáfora de paz, enfatizando os papéis que os homens conferem às mulheres (...)" (p. 633) ${ }^{40}$. As mulheres aparecem apenas nas cláusulas sobre casamentos cruzados e a elas são conferidos os papeis de futuras esposas e mães, assegurando - por meio do casamento — e propagando - por meio dos filhos—a

37 “(...) il n'est plus possible d'accepter le postulat selon lequel le sexe d'un individu l'inscrit automatiquement et naturellement, quel que soit le contexte, dans un réseau de significations spécifiques $(\ldots)$ ".

38 “(...) peut être défini comme un agencement particulier et unique des rapports de sexe dans un contexte historique, documentaire et relationnel spécifique".

39 “(...) socialement très différenciés, insérés dans un réseau complexe de relations, habitant dans quatre communes (...)"

40 “(...) sens symbolique et social de ces mariages croisés, métaphores de la paix, en insistant sur les rôles que les hommes confèrent aux femmes (...)" 
paz (p. 642). Os homens, por sua vez, são dotados da capacidade de negociar a paz (p. 655). Mesmo que saibamos que nenhum desses casamentos foi realizado, a eficácia do documento reside no fato de que, para ser produzido, ele foi negociado e, posteriormente, conservado em um arquivo. Como conclui o autor, o documento “(...) permitiu ao poder pontifício lembrar sua presença [nas comunas em conflito], mostrando seu apego à autonomia das cidades mercantis e à paz, às elites comunais reafirmar sua dominação social, e aos homens manifestar seu poder e seu controle sobre as mulheres" (p. 655) ${ }^{41}$.

A leitura desse quadro social por meio de uma abordagem dos estudos de gênero revelou os papeis sociais a serem desempenhados pelos homens e mulheres dentro desse contexto específico. No presente estudo, mobilizaremos a noção de regimes de gênero não apenas para ressaltar a agência feminina, mas para abordar questões relativas aos lugares sociais ocupados por essas mulheres e às tramas de relações que elas próprias contribuíam para tecer ativamente. Voltemos, então, ao caso paleoassírio.

Por meio das cartas podemos observar as estratégias de retórica escolhidas pelas mulheres através do emprego de uma linguagem específica materializada nos tabletes, que funcionavam como recurso para que se posicionassem socialmente e construíssem seu capital material e simbólico. A própria existência das cartas e toda a mobilidade envolvida na atuação dessas mulheres são uma prova da pluralidade de lugares sociais ocupados por elas, e do fato de que não foram moldadas socialmente para figurarem estritamente no domínio doméstico apenas por serem mulheres.

Gostaríamos de destacar tanto os ambientes de confluência de atividades dessas mulheres com seus parceiros quanto alguns espaços de diferenciação de ações, ou seja, as expressões de diferença de gênero. Acreditamos que as diferenças de gênero, na realidade do Antigo Oriente Próximo, não são a monocausalidade de todos os fenômenos, mas fazem parte dessas sociedades, transpassam e são transpassadas por outras divisões, como classe e idade, por exemplo (Sebillotte-Cuchet, 2012).

Nesse sentido, evidenciaremos algumas características que nos permitem perceber como as distinções sociais, e não apenas de gênero, operam nesse sistema. Levando em

\footnotetext{
41،'Il a permis au pouvoir pontifical de rappeler sa présence en montrant son attachement à l'autonomie des cités marchésanes et à la paix, aux élites communales de réaffirmer leur domination sociale, et aux hommes de manifester leur pouvoir et leur contrôle sur les femmes".
} 
conta a identidade, as idiossincrasias e a pluralidade de mulheres assírias inseridas no contexto do comércio inter-regional do segundo milênio AEC, devemos, portanto, delimitar o lugar social ocupado por essas mulheres realizando não "uma história de mulheres ou uma história de homens e mulheres, mas uma história das distinções sociais" (Sebillotte-Cuchet, 2012, p. 578) ${ }^{42}$.

Ao analisar essa documentação, podemos observar que essas mulheres realizavam a manutenção da unidade doméstica, incluindo o gerenciamento de pessoas e de atividades, e a negociação da aquisição de produtos necessários à sobrevivência da família, como grãos-especialmente cevada — e óleo de gergelim. Como evidenciado anteriormente, o ambiente doméstico não se comporta como uma unidade social isolada, mas articula-se com outros domínios. Uma importante função realizada por essas mulheres era a produção de tecidos que acontecia dentro do domínio doméstico. Por meio das firmas familiares, ao enviar os tecidos que seriam negociados pelos homens da família em Kaneš, essas mulheres recebiam em troca prata e ouro, permitindo sua participação direta no comércio, como veremos a seguir.

Em inúmeros trechos das cartas podemos observar que não apenas os homens cobram pelo envio ou pela qualidade dos tecidos, mas que também as mulheres pedem satisfação em relação ao envio da prata correspondente à sua produção, como é o caso dos trechos das cartas de Lamassī para o seu marido Pūšu-kēn, e de Tarām-Kūbi para o seu marido Innāya:

- "Para Pūšu-kēn diz. Assim [fala] Lamassī: (...) Por que motivo tu me escreves reiteradamente: 'os tecidos que você costuma me enviar não são bons" " (BIN 6, 11) $)^{43}$;

- "Para Innāya diz. Assim [fala] Tarām-Kūbi: (...) aqui eu não posso te enviar em todas as ocasiões tecidos que [são] pesados" (CCT 3, 23b) ${ }^{44}$;

\footnotetext{
42 “(...) une histoire des femmes ou une histoire des hommes et des femmes, mais à écrire une histoire des distinctions sociales".

${ }^{43}$ BIN 6, 11, Linhas 1-2 e 7-11. No texto acadiano temos: “ana Pūšsu-kēn qibì-ma umma Lamassī-ma (...) miššu ša taštanapparanni umma atta-ma șubatū ša tuštenebbilinni la damqū”.

${ }^{44}$ Smith, S. Cuneiform Texts from Cappadocian Tablets in the British Museum part. III, $1925=$ CCT 3, 23b, linhas 1-2 e 5-6. No texto acadiano temos: "ana Innāya qib̄i-ma umma Tarām-Kūbi-ma (...) annakam șubātī ša ikabutu la uštenebbalakkum"
} 
- "Para Pūšu-kēn diz. Assim [fala] Lamassī: (...) Em relação aos tecidos que Aššur-malik lhe entregou anteriormente, por que tu não fazes com que prata me seja enviada?” (RA 59, 159) ${ }^{45}$.

Em outra carta, Lamassī solicita ao seu marido o envio de matéria prima, lã, em um momento que seu custo parece elevar-se em Aššur:

- "Para Pūšu-kēn diz. Assim [fala] Lamassī: Quando tu me enviar a bolsa, coloca nela lã, [porque] a lã é cara na cidade [em Aššur] $(\text { BIN 6, 7 })^{46}$.

Em relação ao trecho acima, sabemos que a remetente não solicita o envio de lã em razão de ela não está disponível no mercado local—como poderia acontecer—, mas sim devido ao aumento do valor desse produto em Aššur. É importante notar que essas mulheres provavelmente realizavam uma avaliação da flutuação do preço da lã necessária para produção de tecidos, colocando-se como agentes dos negócios por meio da tomada de decisões. Ainda que no envio de lã da Anatólia tivesse embutido o custo, provavelmente alto, do transporte (Michel, 2014, pp. 235-236), Lamassī decide efetivar a solicitação materializando o seu desejo no documento apresentado.

Ainda em relação aos empreendimentos familiares, as mulheres, além de produzirem tecidos, eram responsáveis por diversas outras atividades, como: por assegurar sua chegada à Anatólia; por realizar operações financeiras essenciais para a manutenção das redes de comércio, como o registro de mercadorias; por ocuparem-se da gestão dos arquivos e contratos; e por representarem seus maridos frente às autoridades de Aššur, como em casos de disputas judiciais. Nos arquivos dos mercadores estabelecidos em Kaneš também podemos encontrar documentos que evidenciam o controle dos arquivos e o registro de mercadorias. Entretanto, não conhecemos indícios de documentos que mostrem os maridos representando as mulheres em disputas judiciais

\footnotetext{
${ }^{45}$ Garelli, P. Tablettes Cappadociennes de Collections Diverses. RA, n. 59, 1965, p. 159. = RA 59, 159, linhas 1-2 e 35-37. No texto acadiano temos: "ana Pūšu-kēn qibì-ma umma Lamassì-ma (...) șubatī ša Aššur-malik ina pānītim ublanni kaspam min tušébalam” Esse trecho faz referência à leva de tecidos que Lamassī enviou para Kaneš via Aššur-malik e a cobrança relativa à prata por essa produção.

${ }^{46}$ Ferris, J., Old Assyrian Letters and Business Documents. Babylonian Inscriptions in the Collection of J. B. Nies, v. VI, 1944 = BIN 6, 7, Linhas 1-3 e 16-21. No texto acadiano temos: "ana Pūšu-kēn qibì-ma umma Lamassī-ma (...) imūme kīsam tušébalanni šaptam šuknam šaptum ina ālim waqrat”.
} 
Mare Nostrum, ano 2020, v. 11, n. 1 .

(Günbatti, 1992, p. 234; Lion, 2007, pp. 62-63; Michel, 2001, pp. 419-425; 2015; Thomason, 2013, p. 96; Veehnhof; Eidem, 2008, pp. 107-110).

A inserção dessas mulheres nas firmas familiares permitia que elas mobilizassem elementos e se articulassem com novos espaços, adquirindo autonomia e realizando transações de interesses próprios. Podemos observar que elas acumulavam espólios pessoais que iam além de sua herança (dote) ou das joias e objetos advindos de Kaneš, os quais ganhavam como presente. Elas podiam aplicar em outras atividades a prata que recebiam em troca da produção de tecidos, por exemplo, investindo e realizando negócios com outros mercadores, ou também atuando como credoras de pequenas quantidades de prata, cobre e lã no campo do empréstimo a curto prazo e/ou a juros (Michel, 2001, pp. 419-425; 2017, pp. 80-97; Veenhof; Eiden, 2008, pp. 109-110), como podemos ver no trecho abaixo da carta de Ahaha, para seu irmão Aššur-mūtappil:

- "Para Aššur-mūtappil diz. Assim [fala] Ahaha: (...) Eu investi 3 minas e meia $^{47}$ de prata [na sociedade comercial] de Puzur-Aššur" (KTH, 7:15$17)^{48}$.

Apesar de não constar nenhuma palavra nesse trecho que remeta a uma sociedade comercial, em outra carta ${ }^{49}$ Ahaha explicita seu investimento em prata em um naruqqum de Puzur-Aššur, termo acadiano que remete tanto a um tipo de sociedade comercial quanto ao capital investido nesse negócio (Cad N, v.1, p. 379; Michel, 2001, pp. 324326; p. 330).

Por fim, outro aspecto que nos chama a atenção é a maneira pela qual a religião é mobilizada por essas mulheres na documentação epistolar, já que nas cartas enviadas por seus maridos-ao menos nas que chegaram até nós-não há referência a aspectos religiosos da mesma maneira ${ }^{50}$. Elas solicitavam de forma contundente o envio de mais

\footnotetext{
${ }^{47}$ De acordo com Kouwenberg, N. J. C. (2019, p. 181), nesse período uma mina assíria corresponde a cerca de $500 \mathrm{~g}$.

${ }^{48}$ Lewy, J. Die Kültepetexte aus der Sammlung Frida Hahn, Berlin, 1930, p. 12 = KTH 7, linhas 1-2 e 1516. No texto acadiano temos: "ana Ǎ̌šur-mūtappil qib̄i-ma umma Ahaha-ma (...) 3 1/2 manē kaspam ana Puzur-Ǎ̌šr".

${ }^{49}$ Cf. CCT 4, 31b, linhas 4-5.

${ }^{50}$ É importante observar que em outros documentos, como na correspondência de um mercador chamado Innāya, temos o registro de homens interessados por questões religiosas. Entretanto, como afirmamos
} 
prata para destinar às oferendas votivas, bem como solicitavam incisivamente a volta dos seus maridos de Kaneš para que suas filhas fossem entregues ao sacerdócio, ou, nas palavras delas, para que fossem entregues ao deus. Ainda, escreviam para os homens da família sobre as negligências religiosas dos mesmos, às quais atribuíam doenças e problemas da casa de Aššur, como podemos constatar nesses trechos das cartas de Lamassī sobre sua filha Ahaha ao seu marido Pūšu-kēn, e de Tarīš-mātum e sua filha Belātum para seu irmão Pūšu-kēn:

- "Para Pūšu-kēn diz. Assim [fala] Lamassī: (...) A pequena [Ahaha] cresceu muito. Parte e vem [para a cidade de Aššur]. Coloca-a na frente [do deus] Aššur" (CCT 3, 20) $)^{51}$;

- "Para Pūšu-kēn diz. Assim [fala] Tarīš-mātum e Belātum: Agora, por causa da prata da oferenda do deus, Belātum está doente" (KTS 1, 24) $)^{52}$.

Destinar uma filha ao sacerdócio não era apenas uma questão de gratidão ao deus, também implicava na confirmação de uma posição social privilegiada dessas famílias (Michel, 2017, p. 89). Além disso, alguns rituais e cerimônias, como o culto aos mortos (p. 91) ou o envio das filhas ao sacerdócio, parecem ser tarefa social direcionada aos homens. A forma como essas mulheres mobilizavam as questões religiosas nas cartas nos leva a pensar que elas não agiam, necessariamente, como orientadoras da fé, mas que esse zelo em relação aos homens poderia referir-se a uma forma socialmente aceitável de manutenção do contato, reivindicando que seus parceiros retornassem para Aššur e cumprissem essas demandas. Ademais, como aponta Thomason (2013, p. 102), a retórica da religião era mobilizada em algumas cartas junto à cobrança pelo envio de prata, ou seja, o argumento religioso também poderia ser acionado para que os homens cumprissem demandas ligadas ao comércio, como garantir que as mulheres recebessem o que lhes era devido da produção de tecidos.

acima, não temos conhecimento de registros nos quais homens mobilizam esse tipo de temática em relação às suas parceiras. Sobre o aspecto religioso na documentação de Innāya, cf. Michel, 1991, pp. 85-86.

${ }^{51}$ CCT 3, 20, linhas 1-2 e 38-40. No texto acadiano temos: "ana Püšsu-kēn qibī-ma umma Lamassī-ma (...) șuhārtum danniš irtibi tib'ama atalkam ana pāni Ǎššr šukušši”. Vale destacar que Ahaha torna-se uma gubabtum, uma sacerdotisa do deus Aššur.

${ }^{52}$ Lewy, J. Die Altassyrischen Texte Vom Kültepe Bei Kaisarije. Keilschrifttexte in den Antiken Museen Zu Stambul, v. 1, 1926 = KTS 1, 24, linhas 1-5. No texto acadiano temos: "ana Püšu-kēn qibi-ma umma Tarīš-mātum u Belātum-ma aššumi kaspim ša ikribi annakam Bēlatum tamraṣ". 


\section{Conclusão}

A busca por novas abordagens, novos pontos de vista, novas formas de questionar os resquícios de um passado longínquo, pode nos render bons frutos e, principalmente, nos levar a uma percepção inovadora sobre nós mesmos:

Em última análise, o texto não pode deixar de voltar ao fato de que estamos analisando a nós mesmos. Esse é o enigma do gênero que o tornou tão atraente para tantos analistas por tanto tempo — o tráfego de mão dupla de seus efeitos formativos, as formas que ele cria e desfaz, os padrões que podemos e não podemos ver porque somos parte deles. (Franklin, S., 2016, pp. xvii-Xviii) ${ }^{53}$

Ao naturalizar e entrincheirar as mulheres no âmbito doméstico, os homens assumem o papel de atores centrais na construção da sociedade analisada. Nesse sentido, as mulheres seriam consideradas como uma categoria fixa não construída socialmente e, ao codificá-las dentro de um mundo social simplificado, a pluralidade de seus modos de existência seria anulada.

Autoras como Agnès Garcia-Ventura, M. Erica Couto-Ferreira, Saana Svärd e Stephanie Lynn Budin têm feito esforços para introduzir as discussões dos estudos de gênero no campo da Assiriologia resultando em ricas produções ${ }^{54}$. Especificamente em relação ao caso paleoassírio, como evidenciamos anteriormente, também é notável uma maior preocupação em problematizar a agência das mulheres. Procuramos inserir o presente artigo nessas discussões, trazendo uma leitura das cartas paleoassírias através da mobilização da noção de regimes de gênero.

Por meio da leitura dessas cartas, pudemos constatar uma atuação feminina que está implicada em várias camadas ou condições de uma agência que somente a "ausência dos maridos" não seria capaz de produzir. Podemos observar uma variedade de arranjos

\footnotetext{
53 "Ultimately, then, the text cannot help but return to the fact that we are analyzing ourselves. This is the riddle of gender that has made it so attractive to so many analysts for so long - the two-way traffic of its formative effects, the shapes it makes and unmakes, the patterns we both can and cannot see because we are part of them".

${ }^{54}$ Além da produção de cada autora, destacamos os volumes Studying Gender in the Ancient Near East, 2019, editado por Svärd e Garcia-Ventura; e Women in Antiquity: Real Women across the Ancient Word, 2016, editado por Budin e Jean M. Turfa.
} 
possíveis de papeis dentro e fora do domínio doméstico, da ampla atuação e mobilidade feminina dentro de um espaço dinâmico e da reconfiguração dos regimes de gênero a partir de uma nova realidade imposta pela participação das organizações familiares nas redes de comércio. O gênero, nesse sentido, não está autocontido, mas em construção, tornando-se no fluxo da relação com seus pares, com o comércio, com o domínio doméstico, religioso, enfim, em suas diversas esferas de atuação.

Os trechos das cartas enviadas por Lamassī, Tarām-kūbi, Ahaha, Tariš-mātum e Belātum nos revelam as interações sociais dessas mulheres com seus parceiros e nos permitem enxergar um espaço de diferenciação do gênero. Consequentemente, esses indícios nos permitem perceber como os regimes de gênero atuam nesse contexto específico, como essas mulheres se posicionavam, e como elas eram vistas no contexto no qual estavam inseridas; não apenas em cenários de confluência das atividades com seus pares, mas também em espaços discursivos que lhes parecem exclusivos.

Desse modo, o presente artigo buscou apresentar noções inicias sobre as possibilidades da aplicabilidade da noção de regimes de gênero para o campo da Assiriologia, tendo em mente que interrogar esses documentos a partir da perspectiva das teorias de gênero é um meio adicional da leitura do social e pode nos levar a novas descobertas, à revisão de modelos interpretativos e a repensar os processos de formação do próprio conhecimento, da epistemologia.

Recebido em 20.01.2020, aprovado em 06.02.2020. 
Mare Nostrum, ano 2020, v. 11, n. 1 .

\section{REFERÊNCIAS BIBLIOGRÁFICAS}

Adler, M. N. (1907). The Itinerary of Benjamin of Tudela. Critical Text, Translation and Commentary. Oxford University Press.

Altaweel, M. \& Squitieri, A. (2018). Revolutionizing a World. From Small States to Universalism in the Pre-Islamic Near East. UCL Press.

Asher-Grave, J. (1997). Feminist Research and Ancient Mesopotamia: Problems and Prospects. In: Brenner, A.; Fontaine, C. (eds.) Reading the Bible: Approaches, Methods and Strategies (pp. 218-237). Sheffield Academic Press.

Bahrani, Z. (2001). Women of Babylon. Gender and Representation in Mesopotamia. Routledge.

Barjamovic, G. (2011). A History Geography of Anatolia in the Old Assyrian Colony Period. Museum Tusculanum Press e CNI Publications.

Barjamovic, G., Hertel, T. \& Larsen, M. (2012). Ups and Downs at Kaně̌. Chronology, History and Society in the Old Assyrian Period. Nederlands Instituut Voor Het Nabije Oosten. (PIHANS CXX).

Bottéro, J. (1965). La femme dans la Mésopotamie ancienne. In Grimal, P. (ed.) Histoire mondiale de la femme (pp. 158-223). Nouvelle librairie de France.

Budin, S. \& Turfa, J. (2016). Women in Antiquity: Real Women across the Ancient Word. Routledge.

Couto-Ferreira, E. \& Gárcia-Ventura, A. (2014). Engendering Purity and Impurity in Assyriological Studies: A Historiographical Overview. In De Groot, J.; Morgan, S.,(eds.). Gender and the Sacred: Reconfiguring Religion in Gender History (pp. 119-134). Blackwell Publishing Ltd.

Delnero, P. \& Lauinger, J. (2015). (eds). Texts and Contexts: The circulation and the Transmission of Cuneiform Texts in Social Space. Studies in Ancient Near East Records, v.9. Berlim: De Gruyter. 
Anita Fattori. Atuação de mulheres assírias nas redes de comércio.

Franklin, S. (2016). The Riddle of Gender. In Strathern, M. Before and After Gender: Sexual Mythologies of Everyday Life (pp. xiii-xlv). HAU Books.

Ferris, J. (1944). Old Assyrian Letters and Business Documents. Babylonian Inscriptions in the Collection of J. B. Nies, v. VI. Abreviação BIN 6.

Garcia-Ventura, A. (2016a). Investigación feminista, historia de las mujeres y mujeres en la historia en los estudios sobre Próximo Oriente Antiguo. Revista de Estudos Culturais, $\mathrm{n} 3$.

Garcia-Ventura, A. (2016b). Vidas de mujeres en la antigua Mesopotamia. Historia Abierta, 20-24.

Garcia-Ventura, A. \& Justel, J. (2018). Las mujeres en el Oriente cuneiforme. Una aproximación desde la Historia de las Mujeres y los Estudios de Género. In GarciaVentura, A. \& Justel, J (ed.) Las mujeres en el Oriente cuneiforme (pp. 23-42). Servicio de Publicaciones de la Universidad de Alcalá: Alcalá de Henares.

Garcia-Ventura, A. \& Zisa, G. (2017). Gender and Women in Ancient Near Eastern Studies Bibliography 2002-2016. Akkadica, 138, 37-67.

Garelli, P. (1965). Tablettes Cappadociennes de Collections Diverses. RA, 59.

Günbatti, C. (1992). Some observations about the commercial activities of women in the light of the Kültepe Tablets. Mél. S. Alp, 229-234.

Harris, R. (2000). Gender and Aging in Mesopotamia. The Gilgamesh Epic and Other Ancient Literature. University of Oklahoma Press.

Heródoto, (2019). História, volume 1, (3ª Ed.). Editora Nova Fronteira.

Hicks, D. (2010). The material-cultural turn. Event and effect. In Hicks, D. \& Beaudry, M. (eds.) The Oxford handbook of material culture studies. Oxford University Press.

Larsen, M. (1996) The Conquest of Assyria. Excavations in an antique land. 1840-1860. Oxon, Nova Iorque: Routledge.

Larsen, M. (2007). Individual and Family in Old Assyrian Society. JCS 59, 93-106. 
Mare Nostrum, ano 2020, v. 11, n. 1 .

Larsen, M. (2015). Ancient Kaneš: A Merchant Colony in Bronze Age Anatolia. Cambridge University Press.

Lett, D. (2012a). Genre et paix. Des mariages croisés entre quatre communes de la Marche d'Ancône en 1306. Annales HSS 67 (3), 629-655.

Lett, D. (2012b). Les régimes de genre dans les sociétés occidentales de l'Antiquité au XVII ${ }^{\mathrm{e}}$ siècle. Annales HSS, 67 (3), 563-572.

Lewy, J. (1926). Die Altassyrischen Texte Vom Kültepe Bei Kaisarije. Keilschrifttexte in den Antiken Museen Zu Stambul, v. 1. Abreviação KTS 1.

Lewy, J. (1930). Die Kültepetexte aus der Sammlung Frida Hahn, Berlin. Abreviação KTH.

Lion, B. (2007). La notion de genre en assyriologie. In: CUCHET, V. \& ERNOULT, N. (eds.) Problèmes du genre en Grèce Ancienne (pp. 51-64). Publications de la Sorbonne.

Lion, B. \& MICHEL, C. (Oct. 2007). Jules Oppert et le syllabaire akkadien. Colloque Histoire de déchiffrements. Nanterre, França, 81-94. Recuperado em 6 janeiro, 2020. https://hal-paris1.archives-ouvertes.fr/halshs-00781407/fr/.

Michel, C. (1991). Innāya dans les tablettes Paléo-Assyriennes. V.1. Editions Recherche sur les Civilisations.

Michel, C. (2001). Correspondance des marchands de Kanish au début du IIe millénaire avant J.-C. Les éditions du Cerf. (Littératures anciennes du Proche-Orient. v. 19).

Michel, C. (2004). La production textile privée à Assur au début du 1 millénaire avant J.C. Cahier des thèmes transversaux ArScAn, 5, 2003/2004, 164-169.

Michel, C. (2006). Femmes et production textile à Assur au début du IIe millénaire avant J.-C. Techniques \& culture, 46, 281-297.

Michel, C. (2008). Femmes au foyer et femmes en voyage. Clio. Histoire, femmes et sociétés, 28, 17-38.

Michel, C. (2009). Les femmes et l'écrit dans les archives paléo-assyriennes (XIXe s. av. 
Anita Fattori. Atuação de mulheres assírias nas redes de comércio.

J.-C.). Topoi Suppléments, v. 10, 253-272.

Michel, C. (2014). Wool Trade in Upper Mesopotamia and Syria According to Old Babylonian and Old Assyrian Texts. In Breniquet, C. \& Michel, C. (Eds.) Wool Economy in the Ancient Near East and the Aegean. From the Beginnings of Sheep Husbandry to Institutional Textile Industry (pp. 232-254). OXBOW BOOKS.

Michel, C. (2015). Quelle place occupent les femmes dans les sources cunéiformes de la pratique? Genre et archéologie, 140, 46-50.

Michel, C. (2017). Economy, Society, and Daily Life in the Old Assyrian Period. In Frahm, E. (ed.) A Companion to Assyria (pp. 80-107). Wiley Blackwell.

Michel, C. (2018). Constitution, Contents, Filing and Use of Private Archives. In Kienitz, S. \& Friedrich, M.; Brockmann, C. (eds.) Manuscripts and Archives: Comparative Views on Record-Keeping (pp. 43-70). De Gruyter.

Michel, C. (no prelo). Women from Ǎ̌šur and Kaniš. Writings from the Ancient Word. SBL.

Rede, M. (2007). Família e Patrimônio na Antiga Mesopotâmia. MAUAD Editora Ltda.

Rocha, T. (2018). Reassessing Models in Gender and Domestic Space in New Kingdom Workmen's Villages. In Budin, S., Cifarelli, M., Garcia-Ventura, A. \& Albà, A. (eds.) Gender and Methodology in the Ancient Near East: Approaches from Assyriology and beyond (pp. 299-312). Barcino Monographica Orientalia 10. Universitat de Barcelona Edicions.

Rubin, G. O Tráfico de Mulheres (1975/2017). In Políticas do Sexo (pp. 8-61). Ubu Editora.

Sebillotte-Cuchet, V. (2012). Régimes de genre et Antiquité grecque classique (Ve-IVe siècles av. J.- C.). Annales. Histoire, Sciences Sociales, 573-603.

Smith, S. (1927). Cuneiform Texts from Cappadocian Tablets in the British Museum. Parte III. Abreviação CCT 3. 
Mare Nostrum, ano 2020, v. 11, n. 1 .

Smith, S. (1927). Cuneiform Texts from Cappadocian Tablets in the British Museum. Parte IV. Abreviação CCT 4.

Stratford, E. (2017). A Year of Vengeance. Time, Narrative, and the Old Assyrian Trade. SANER, 17 (1). De Gruyter.

Strathern, M. (2016). Before and After Gender: Sexual Mythologies of Everyday Life. HAU Books.

Svärd, S. (2015). Women and Power in Neo-Assyrian Palaces. State Archives of Assyria. Studies 23. Indiana.

Svärd, S. \& Garcia-Ventura, A. (2018). (eds.) Studying Gender in the Ancient Near East (pp. 413-422). Eisenbrauns.

The Assyrian Dictionary of the Oriental Institute of the University of Chicago (19562010). 21 volumes. Abreviação CAD.

Thomason, A. (2013). Her Share of the Profits: Women, Agency, and Textile Production at Kültepe/Kaneš in the early second millennium BC. In Nosch, M.-L., Koefoed, H. \& Andersson Strand, E. (eds.) Textile Production and Consumption in the Ancient Near East. Archaeology, Epigraphy and Iconography (pp. 93-112).

Thomason, A. (2018). After "Profits": Methodological and Historiographic Remarks on the Study of Women, Textiles and Economy in the Ancient Near East. In Svärd, S. \& Garcia-Ventura, A. (eds.). Studying Gender in the Ancient Near East (pp. 413422). Eisenbrauns.

Veenhof, K. (1977). Some Social Effects of Old Assyrian Trade. Iraq, 39, 109-118.

Veenhof, K. (2003). Archives of Old Assyrian Traders. In Brosius, M (ed.) Ancient Achieves and Archival Traditions, 78-123.

Veenhof, K. (2008). Communication in the Old Assyrian Trading Society by Caravans, Travelers and Messengers. In Michel, C. (Ed.). Old Assyrian Studies in Memory of Paul Garelli (pp. 199-246). Nederlands Instituut Voor Het Nabike Oosten.

Veenhof, K. (2013). The Archives of Old Assyrian Traders: their Nature, Functions and 
Anita Fattori. Atuação de mulheres assírias nas redes de comércio.

use In Faraguna, M. (ed.) Archives and archival documents in ancient societies: Legal documents in ancient societies IV (Trieste 30 September - 1 October 2011) (pp. 27-71). EUT Edizioni Università di Trieste.

Veenhof, K. (2014). Families of Old Assyrian Traders. In Marti, L. (Ed.) La Famille dans le Proche-Orient Ancien: réalités, symboles et images (pp. 341-374). Winona Lake.

Veenhof, K. (2017). The Old Assyrian Period (20th-18th Century BCE). In Frahm, E. (ed.) A Companion to Assyria (pp. 57-79). Wiley Blackwell.

Veenhof, K. \& Eidem, J. (2008). Mesopotamia. The Old Assyrian Period. OBO 160 (5). Academic Press Fribourg.

Veldhuis, N. (2018). Gender Studies and Assyriology: Expectations of an Outsider. In Svärd, S. \& Garcia-Ventura, A. (eds.). Studying Gender in the Ancient Near East (pp. 447-460). Eisenbrauns.

Von Dassow, E. (2018). Figure and Ground: Reading Ancient Near East Sources. In Simpson, E. (Org.). The Adventure of the Illustrious Scholar. Papers Presented to Oscar White Muscarella (pp. 818-838). Brill. 


\section{Performance OF ASSYRIAN WOMEN in THE INTER-REgional Trade NeTWORKS OF THE 2ND MILlENNIUM BCE: POSSIBILITIES OF GENDER APPROACHES IN THE STUdies OF AnCIENT Mesopotamia}

Anita Fattori

\section{ABSTRACT}

The theoretical perspective of gender has recently been incorporated into assyriological studies, and the results of its use have outlined new approaches to the understanding of the societies of the Ancient Near Eastern. At the beginning of the second millennium BCE, the city of Aššur stands out in this scenario for its central role in an important long-distance commercial network. The Assyrians, organized into Family enterprises, traded textile and tin in exchange for gold and silver. The letters exchanged between the merchants highlighted the active participation of women in Family enterprises. Most of those letters, whose main destination was Anatolia and their families which remained in Aššur, were sent of received by women. Therefore, this correspondence is an important documental source for the study of women in the Mesopotamian context. From the perspective of gender regimes, we intend to present some aspects of Assyrian women's performance in the context of interregional commerce of the beginning of the second millennium BCE to understand some of the dimensions of their social roles.

KEYWORDS

Mesopotamia; old assyrian period; gender regimes. 